Daniel L. Thornton is a vice president and economist and David C. Wheelock is an assistant vice president and economist at the Federal Reserve Bank of St. Louis. Heidi L. Beyer provided research assistance.

\title{
A History of the Asymmetric Policy Directive
}

\section{Daniel L. Thornton and David C. Wheelock}

$T^{\mathrm{h}}$ he Federal Open Market Committee (FOMC) is the Federal Reserve System's principal monetary policy-making committee. ${ }^{1}$ At the conclusion of each FOMC meeting, the Committee issues operating instructions, known as the "directive," to the Open Market Trading Desk at the Federal Reserve Bank of New York. From 1983 through 1999, these instructions included a statement about the Committee's expectations for future changes in the stance of monetary policy, in addition to instructions for current policy. The statement pertaining to possible future policy was known as the "symmetry," "tilt," or "bias," of the policy directive. The directive was said to be symmetric if it indicated that a tightening or an easing of policy were equally likely in the future. Otherwise, the directive was said to be asymmetric toward either tightening or easing.

Since February 1994, the FOMC has publicly announced changes in current monetary policy immediately upon making them. Before May 1999, public announcements made at the conclusion of FOMC meetings did not indicate whether the FOMC had issued an asymmetric directive. From May to December 1999, however, announcements following FOMC meetings included a statement of the Committee's expectation about the direction of future policy action, regardless of whether an action was taken at that meeting. This practice attracted considerable attention and much speculation about how to interpret statements about possible future policy changes. The Fed has never provided an official interpretation of these statements. To help clarify its intentions, the FOMC established a subcommittee to review both its policy directive and the public announcement following FOMC meetings. In January 2000, the FOMC announced that the public statement issued at the conclusion of future FOMC meetings will indicate any immediate change in the stance of policy, as well as the Committee's assessment of the balance of risks between heightened inflation pressure and economic weakness over the foreseeable future. The new language, however, is not intended to indicate the likely direction or the timing of future policy moves.

The January 2000 announcement appears to bring to a close a distinct period in the history of Federal Reserve operating procedures. This article will review the history and implementation of asymmetry in FOMC policy directives between 1983 and 1999. Researchers and market participants have suggested at least three interpretations of the FOMC's use of asymmetric language. One is based on the belief that the FOMC chairman has discretion to adjust the stance of policy by small amounts between FOMC meetings without consulting the full Committee. An asymmetric directive, according to this interpretation, granted the chairman authority to make larger intermeeting policy changes in the direction specified by the asymmetric language than he otherwise was permitted to make.

A second interpretation holds that the issuance of an asymmetric directive indicated that the FOMC was more likely to change the stance of policy either before or at the next FOMC meeting, than if a symmetric directive had been issued. Asymmetric language also is thought to have indicated the most likely direction of the policy action. Some observers interpret asymmetry as pertaining just to the intermeeting period, while others contend that asymmetry signaled likely changes in policy at the next FOMC meeting. Before 1994, the FOMC often changed its policy stance between meetings. Since 1994, however, it has rarely done so, suggesting a possible change in the horizon over which asymmetric language pertained.

A third interpretation is that asymmetric directives primarily were used to build consensus among the voting FOMC members. For example, if several members of the Committee desired to tighten policy

\footnotetext{
${ }^{1}$ The FOMC consists of the seven members of the Board of Governors of the Federal Reserve System and the presidents of the 12 Federal Reserve Banks. All Board members are voting members of the FOMC, and the Board chairman serves as FOMC chairman. The president of the Federal Reserve Bank of New York serves as FOMC vice chairman, and is a permanent voting member. The presidents of the remaining Reserve Banks have four votes, which rotate among them on a fixed schedule. Appendix A contains a listing of the members of the Board of Governors and Federal Reserve Bank presidents who served between 1983 and 1999 .
} 
immediately, but most of the Committee did not, the members favoring an immediate tightening might have been more inclined to vote with the majority if the directive was made asymmetric towards tightening. Likewise, if some members favored no change, but the majority preferred to tighten, those preferring no change might have been more inclined to support an immediate tightening if the directive was symmetric.

Of course, these interpretations are not mutually exclusive. For example, asymmetric directives would seem to have been most useful for building consensus if members believed that adopting such language affected the likelihood of a future change in the stance of policy. Indeed, an asymmetric directive could have been used to form a consensus while at the same time giving the chairman additional leeway to change the stance of policy or indicating the likely direction of the next policy move.

This article attempts to gauge the validity of the different interpretations of the use of asymmetric policy directives by investigating the extent to which they are supported by historical experience. Specifically, we examine documentary evidence to determine the intent of FOMC members when asymmetry was first introduced into the directive in 1983. We also investigate the extent to which the behavior of the FOMC was consistent with any of these interpretations.

The article has three sections. The first describes the evolution of the directive between 1983 and 1999, and investigates the intentions of FOMC members when asymmetric language was first included in the directive. The second section presents statistical evidence concerning the three interpretations of the asymmetric directive. The third section presents a summary and conclusions.

\section{THE EVOLUTION OF THE ASYMMETRIC POLICY DIRECTIVE}

The FOMC policy directive is a general statement of instructions the Committee issues to the Trading Desk at the Federal Reserve Bank of New York (hereafter, "the Desk"). The directive contains a statement of long-run policy objectives and policy instructions for the immediate future. The directive is intentionally vague about specific actions to take, however, leaving it to the Desk to determine the open market operations necessary to achieve the FOMC's objectives.

The current directive instructs the Desk to achieve a specific target for the federal funds rate. Before 2000, the directive also included language pertaining to possible future changes in the target. For example, the directive issued on October 5, 1999, contained the following instructions:

\section{To promote the Committee's long-run objectives of price stability and sustainable economic growth, the Committee in the immediate future seeks con- ditions in reserve markets consistent with main- taining the federal funds rate at an average of around 5-1/4 percent. In view of the evidence currently available, the Committee believes that prospective developments are more likely to war- rant an increase than a decrease in the federal funds rate operating objective during the inter- meeting period.}

This directive specifies no immediate change in policy, defined as a change in the Committee's objective for the federal funds rate. The directive is, however, asymmetric toward a future tightening of policy. By contrast, the directive issued at the August 24,1999 , meeting indicated that

\section{... the Committee in the immediate future seeks conditions in reserve markets consistent with increasing the federal funds rate to an average of around 5-1/4 percent. In view of the evidence currently available, the Committee believes that prospective developments are equally likely to warrant an increase or a decrease in the federal funds rate operating objective during the inter- meeting period.}

This directive specifies an immediate tightening of policy, reflected in an increase in the federal funds rate target (from 5 to 5.25 percent), but indicates no bias, or asymmetry, toward additional tightening or toward easing in the future.

The FOMC directive has included a specific target for the federal funds rate only since August 1997. Before then, operating instructions were written in terms of the degree of restraint to be applied to commercial bank reserve positions. Any asymmetry was indicated by statements to the effect that different degrees of restraint "would" or "might" be acceptable to the Committee depending on the outcome of some specified condition(s). For example, the directive issued in July 1997 stated:

In the implementation of policy for the immediate future, the Committee seeks to maintain the existing degree of pressure on reserve posi- 
tions. In the context of the Committee's long-run objectives for price stability and sustainable economic growth, and giving careful consideration to economic, financial, and monetary developments, somewhat greater reserve restraint would or slightly lesser reserve restraint might be acceptable in the intermeeting period. The contemplated reserve conditions are expected to be consistent with moderate growth in M2 and M3 over coming months. (Emphasis added.)

This directive called for no immediate change in policy, but was biased toward a future tightening. This bias is indicated by the phrase "somewhat greater reserve restraint would or slightly lesser reserve restraint might be acceptable in the intermeeting period." The bias is toward a tighter policy because by convention the words "somewhat" and "would" are stronger than the words "slightly" and "might." Both "somewhat" and "would" need not appear in the directive to convey asymmetry in one direction, so long as possible policy changes in the opposite direction are referred to with weaker language (Meulendyke, 1998, pp. 137-38; Ritter, 1993, pp. 32-33). Although cumbersome, the directive was phrased this way to convey the Committee's intent while providing sufficient flexibility to implement policy during the intermeeting period.

Except for replacing the phrase indicating the desired degree of "restraint on reserve positions" with explicit reference to an intended federal funds rate, this form of the directive has been used since 1983. The specific language of the operating instructions portion of the directive has, however, evolved over time. Throughout much of the 1980s, operating instructions were crafted at each FOMC meeting, with phrases added, deleted, or modified from one meeting to the next. Eventually, the Committee settled on language that could be used in all directives, so that policy decisions could be conveyed simply by inserting the appropriate word or phrase into otherwise standard language.

\section{The Original Intent of Asymmetry}

Except for introducing a specific target for the federal funds rate, the language used to convey operating instructions in FOMC directives has changed little since 1983. Language to indicate possible future policy changes was used first in the directive issued on February 9, 1983. The operating instructions contained in that directive were worded as follows:
For the more immediate future, the Committee seeks to maintain the existing degree of restraint on reserve positions. Lesser restraint would be acceptable in the context of appreciable slowing of growth in the monetary aggregates to or below the paths implied by the long-term ranges, taking account of the distortions relating to the introduction of new accounts. The Chairman may call for Committee consultation if it appears to the Manager for Domestic Operations that pursuit of the monetary objectives and related reserve paths during the period before the next meeting is likely to be associated with a federal funds rate persistently outside a range of 6 to 10 percent. (Emphasis added.)

During the early 1980s, the FOMC grappled with the challenge of formulating monetary policy when the growth rates and velocities of monetary and credit aggregates were behaving unpredictably. In October 1982, the FOMC changed its operating procedure to substantially de-emphasize control of the monetary aggregates, particularly M1. The FOMC continued to monitor the growth of the aggregates and set growthrate monitoring ranges for M2, M3, and credit, believing that the aggregates provided useful information for setting policy. Several members of the Committee, however, argued that the aggregates by themselves were unreliable targets for setting policy in the short run. At the FOMC meeting of February 8-9, 1983, Fed Chairman Paul Volcker stated:

What I hear around the table ... is unanimity on targeting [money], which is where we were before, and a lot of flexibility. I think those are fundamentally incompatible in a conceptual sense.... I wouldn't go all the way to targeting interest rates very firmly because I think there are targets other than interest rates that we could adopt instead of monetary targeting... There are a lot of variables and a lot of nuances - or more than nuances - of differences as to what to do with all these variables. And how we condense all that into a directive is the problem. (Transcript of FOMC Meeting of February 8-9, 1983, pp. 32-33.)

In formulating policy during early 1983, the FOMC faced uncertainty about the strength of the ongoing economic expansion, particularly in the face of threatening financial instability associated with debt defaults by developing countries. Inflation also remained un- 
acceptably high, and despite distortions in the monetary aggregates caused by ongoing deregulation of depository institution accounts, some FOMC members were concerned that rapid money stock growth would spark even higher inflation. On the other hand, a few members, more concerned about the outlook for economic activity than about rapid money growth, pressed for an immediate easing of policy. Federal Reserve Bank of Kansas City President Roger Guffey, for example, stated: "I ... suggest that we do want to cut the rates without regard to the [monetary] aggregates because we have no control over those. Our focus should be on the economy and the recovery." (FOMC transcript, Feb. 8-9, 1983, p. 85.) Governor Henry Wallich disagreed:

I think it would take a real collapse of the growth rate of the aggregates to justify reducing interest rates under present conditions. ... If the aggregates remain half-way strong and the economy expands moderately, I don't think that's the time to reduce interest rates. (FOMC transcript, Feb. 8-9, 1983, p. 85.)

Other members of the Committee split along these lines as well.

In an effort to craft operating instructions to the Desk in light of such diverse opinions among FOMC members, Chairman Paul Volcker suggested introducing language that called for policy easing during the intermeeting period if the growth of the aggregates slowed:

Let me just put on the table an alternative proposal for the first sentence [of the operating portion of the directive] and at least explore what we want to do in substance. Suppose we just say 'For the more immediate future, the Committee seeks to maintain the existing degree of reserve restraint expecting that that will be consistent with some slowing of the aggregates.' If we want to go further and consider what would be very nice if it happens, 'Lesser restraint would be acceptable in the context of appreciable slowing of growth in the aggregates.' It leaves open the question of how we quantify this or whether we quantify it at all in the directive. I think what that says is that we don't want to tighten up on this next seven-week period as we see it now and we don't want to ease up unless the aggregates turn in a favorable direction. I would make that view fairly explicit. (FOMC transcript, Feb. 8-9, 1983, p. 82.)
In response to a request for clarification, Volcker explained that his second sentence was not an alternative proposal, but rather a contingency:

[This sentence] is not an alternative; it just takes care of another possibility - a further (action) not for today. The first [sentence] says we will maintain the existing degree of reserve restraint; the second [sentence] says lesser restraint would be acceptable in the context of appreciable slowing of grow th in the aggregates. That would not be for today but if the aggregates came in low in the next three or four weeks, we would ease. (FOMC transcript, Feb. 8-9, 1983, pp. 82-83.)

The Committee's discussion then turned to the criteria that would trigger an easing during the intermeeting period. Some members, particularly those favoring an immediate easing, argued that policy actions should not be based on growth of monetary aggregates. Most, however, favored basing contingency action at least in part on the behavior of the aggregates. Volcker suggested that the contingency clause could be written as follows: "lesser restraint would be acceptable in the context of appreciable slowing in the growth of the aggregates or signs of more business weakness..." (FOMC transcript, Feb. 8-9, 1983, p. 85.) Eventually, however, the Committee decided to refer only to growth of the aggregates in the contingency clause. Still, general economic conditions were implicit in the Committee's intentions, and a substantial slowing of the aggregates would not necessarily force a policy easing if the economy continued to expand rapidly. Volcker stated:

All that it [the contingency clause] says is lesser
restraint would be acceptable. I can imagine circum-
stances in which we wouldn't want to do it because
the economy looks so strong. ... I don't think this
binds us to ease if suddenly the economy were taking
off and these aggregates came in low for a few
weeks. (FOMC transcript, Feb. 8-9, 1983, p. 95.)

One apparent reason for writing a bias towards ease in the February 1983 directive was to eliminate any possibility of an intermeeting tightening of monetary policy without another Committee meeting. It was Volcker who raised the issue by asking: "Do we want, in effect, to foreclose a tightening in the coming weeks?" According to the transcript of the meeting, several members replied: "Yes" (FOMC transcript, Feb. 8-9, 1983, p. 86). A bit later, Volcker stated: 
"Quite explicitly we're saying we'd be very reluctant to tighten during these next seven weeks." Governor Charles Partee added: "As a matter of fact, it says we won't tighten." (FOMC transcript, Feb. 8-9, 1983, p. 96.)

A final question the Committee addressed when writing asymmetric language into the policy directive was whether to quantify contingency clauses, for example to specify the extent that monetary aggregate growth rates had to slow in order to trigger a policy easing. Governor Lyle Gramley suggested that the contingency clause should be specific: "To put out an operating paragraph which says, in effect, that we have some numbers and we're going to act in accordance with them but we're not going to tell you what they are, doesn't seem like a reasonable way to proceed." (FOMC transcript, Feb. 8-9, 1983, p. 92.) The Committee decided, however, to follow Governor Wallich's suggestion: "I would not put numbers in [the directive] because it's so uncertain, but I would refer to the longer-term ranges and say if the actual numbers fall significantly below most of those and we have a collapse in the aggregates then yes, (we would ease)." (FOMC transcript, Feb. 8-9, 1983, p. 93.)

The transcript of the February 8-9, 1983, FOMC meeting provides a fairly clear picture of why asymmetric language was introduced into the policy directive and what it was intended to mean. At that time, FOMC members held divergent views about the appropriate targets and short-term goals of monetary policy, and by defining the conditions that could trigger an intermeeting policy action, the asymmetric language seems to have helped forge agreement between those members favoring an immediate easing of policy and those who opposed easing because of rapid monetary aggregate growth. Specifically, the directive indicated that an explicit easing of policy would be acceptable to the Committee if the growth of monetary aggregates slowed. Presumably, such easing would occur at the discretion of the chairman, perhaps in consultation with other officials, but would not require a vote of the full Committee. Moreover, as Volcker suggested, the asymmetric language did not compel the Fed to act even if the stated condition, in this case a slowing of monetary growth, occurred. Presumably, subsequent directives could issue more specific instructions if the Committee felt that the chairman overstepped his authority or failed to act as the Committee had intended. The transcript makes clear, however, that by including asymmetric language, the Committee intended to forestall any policy move in the direction opposite the specified asymmetry.

\section{OPEN MARKET POLICY UNDER ASYM- METRIC DIRECTIVES}

We now examine quantitatively the history of FOMC policy actions since February 9, 1983. The purpose of this section is to investigate the extent to which the symmetry of the directive and the Committee's behavior was consistent with any of the three possible interpretations of an asymmetric policy directive discussed above.

We begin by identifying the FOMC policy directive that was in effect on each business day between February 9, 1983, and November 30, 1999. We assume that a directive became effective on the day that the FOMC voted for it. In the case of two-day meetings, the directive always took effect on the second day. A policy directive stayed in effect until the Committee voted on a new directive. ${ }^{2}$

Our sample includes 4,201 business days. Of these, the directive was symmetric on 1,764 days, biased toward ease on 1,113 days, and biased toward restraint on 1,324 days. There were 135 FOMC meetings during the period and the symmetry of the directive was changed 59 times. All but one change was made at a regularly scheduled FOMC meeting. The exception resulted from a Committee conference call on March 20, 1984.

\section{Policy Actions and the Symmetry of the Policy Directive}

To investigate the relationship between the symmetry of the policy directive and subsequent policy actions of the Fed, we focus on the FOMC's target for the federal funds rate. Our data, which are printed in Appendix B, cover the period February 9, 1983, to November 30, 1999, and have been widely used by researchers. $^{3}$

Care must be taken in interpreting federal funds rate target changes. Prior to August 1997, FOMC policy directives instructed the Desk to maintain, increase, or decrease the extent of restraint on commercial bank reserve positions. In October 1982, the FOMC adopted a borrowed reserves operating target and began to measure reserve restraint in terms of the

\footnotetext{
${ }^{2}$ FOMC directives and meeting summaries are published in the Federal Reserve Bulletin and the Annual Report of the Board of Governors of the Federal Reserve System.

${ }^{3}$ Federal funds rate target changes for the period 1984-93 are from Rudebusch (1995); data for 1983 were kindly provided by Spence Hilton. Data for 1994-99 are based on public announcements following FOMC meetings.
} 
level of borrowed reserves. What we refer to as the funds rate target was then called the "associated federal funds rate," which was defined as the middle of "the federal funds rate trading area that is expected to be consistent with the borrowing assumption." (Sternlight, 1992, p. 81.)

FOMC meeting transcripts from the early and mid-1980s make clear that in policy discussions some FOMC members focused more on the federal funds rate than on the level of borrowed reserves. And, over time, the level of borrowings was deemphasized in favor of an explicit federal funds rate target. While the Fed never formally abandoned its borrowed reserves operating procedure, Alan Greenspan (1997) states that "increasingly since 1982 we have been setting the funds rate directly in response to a wide variety of factors and forecasts." Researchers also contend that the FOMC substantially de-emphasized borrowed reserves as an operating target in favor of the federal funds rate well before 1997 (Muelendyke, 1998; Thornton, 1988). Hence, we investigate the relationship between the symmetry of FOMC directives and the timing and direction of changes in the federal funds rate target throughout the period we study.

Our data set records 122 changes in the funds rate target between February 9, 1983, and November 30, 1999. Some of these changes probably did not reflect changes in the stance of monetary policy, however, but rather were technical adjustments of the expected funds rate in response to changes in the demand for reserves. An unofficial summary of monetary policy actions prepared by staff of the FOMC Secretariat indicates that between 1983 and 1989, only 49 funds rate target changes were associated with changes in policy (see Appendix B). Our data set, by contrast, contains 87 changes in the intended funds rate during the period. Hence, our data may contain as many as 38 target changes during 1983-89 that are characterized better as technical adjustments reflecting changes in reserve demand than as policy actions. Because of this possibility, for all hypotheses described in the paper, we performed test statistics based on both the full data set, and a data set consisting of just those target changes described by the FOMC Secretariat as associated with policy changes. Qualitatively, none of our conclusions are affected by the choice of series on funds rate target changes.

During our sample period there were 135 FOMC meetings and 59 occasions when the symmetry of the directive was changed. Before February 1994, when the FOMC began disclosing policy actions immediately upon taking them, most target changes were made between FOMC meetings. ${ }^{4}$ Of the 105 target changes made prior to 1994, only nine were made at regularly scheduled FOMC meetings. ${ }^{5}$ By contrast, of the 17 target changes since 1994, 15 were made at regularly scheduled FOMC meetings; only two were made between meetings. Since 1994, the FOMC routinely has announced its federal funds rate target. Data covering the period before 1994 record target changes as being implemented one day after the date of FOMC meetings. For the subsequent period, target changes are recorded as occurring on the date of FOMC meetings (on the second day in the case of two-day meetings).

Changes in the funds rate target and the symmetry of policy directives in effect at the time of target changes are summarized in Table 1. Between 1983 and 1999, the federal funds rate target was reduced 33 times when the directive issued at the previous FOMC meeting was biased toward ease. The target was lowered 29 times when the previously issued directive contained no bias, and it was lowered twice when the directive was biased toward tightening. During this period, the funds rate target was increased six times when the directive issued at the previous meeting was biased toward ease, increased 13 times when the directive was unbiased, and raised 39 times when the directive was biased toward tightening.

Prior to 1994 , the Fed made a number of intermeeting funds rate target changes of just 6.25 basis points. Such small changes might best be considered technical adjustments, rather than changes in policy. The number of target changes listed in parentheses in Table 1 include only those larger than 6.25 basis points in absolute value.

Of the 80 target changes we identify as being made when the directive was asymmetric, only eight target changes were in the direction opposite that specified by the asymmetry of the directive. All eight of these appear to have been in response to unexpected changes

\footnotetext{
${ }^{4}$ The Fed began to announce target changes immediately upon making them at the February 1994 FOMC meeting. The policy of doing so, however, was not formally adopted until February 1995

${ }^{5}$ Seventeen target changes are recorded as being implemented one day after an FOMC meeting during this period. Of these, nine were consistent with the instructions for immediate implementation issued in the directive of those meetings. We treat the remaining eight target changes as being intermeeting changes. Of these eight, two (occurring on October 5, 1983, and February 11, 1988) took place when the instructions called for maintaining the reduced pressure on reserve positions. Five others were consistent with the language in the directive pertaining to bias. Our results are not affected qualitatively by whether we treat these eight target changes as occurring on meeting dates or as intermeeting changes.
} 
in reserve demand and, hence, should be considered as technical adjustments.

One of the target cuts was a 6.25 basis point reduction on July 11, 1985. The shock to reserve demand appears to have been temporary because the reduction was reversed on July 25 . The other reduction occurred on July 2,1987, when the funds rate was cut by 12.5 basis points. This cut also was reversed, though not as quickly as the one on July 11, 1985. The funds rate target was increased to its previous level on August 27, 1987.

Of the six target-rate increases, three occurred early in the new operating procedure and in quick succession on July 20, 1983, July 27, 1983, and August 17, 1983. The other cases occurred on March 1 and March 15, 1984, and on January 24, 1985. All three appear to have been in response to increased reserve demand that was not reflected in bank borrowing. For example, according to the Report of Open Market Operations, which is prepared at the end of each reserve maintenance period by the Federal Reserve Bank of New York, the March 15, 1984, increase of 37.5 basis points reflected pressure on reserve demand and the funds rate associated with "the corporate tax date on March 15 and subsequent end-of-quarter pressures."

Unlike the July 11,1985 , and July 2,1987 , target rate cuts, none of the target increases that were made when the directive was biased toward ease were temporary. Indeed, the March 1, 1984, increase was the first of nine consecutive increases, while the increase on January 24, 1985, was the first of four consecutive increases. Nevertheless, all of these changes appear to have been made in response to unexpected changes in market conditions and may not have reflected fundamental changes in the stance of monetary policy.

After 1987, no change in the federal funds rate target was in the direction opposite the asymmetry, if any, specified in the policy directive issued at the previous FOMC meeting. Hence, historically, when the FOMC's policy directive has been asymmetric, the majority of any policy actions taken have been in the direction indicated by the asymmetry. Thus, for target changes made under asymmetric directives, the direction of asymmetry nearly always correctly predicts the direction of the target change. ${ }^{6}$

\section{Symmetry and Fed Policy Actions}

Although the direction of asymmetry signaled the likely direction of any target changes the FOMC made under an asymmetric directive, the question
Table 1

\section{Policy Actions and the Bias in the Policy Directive}

\begin{tabular}{lccc}
\multicolumn{4}{c}{ Policy Action Taken } \\
\hline Bias & $\downarrow F F^{*}$ & $\uparrow F F^{*}$ & Total \\
\hline Ease & $33(31)$ & $6(5)$ & $39(36)$ \\
Symmetric & $29(27)$ & $13(10)$ & $42(37)$ \\
Tight & $2(1)$ & $39(30)$ & $41(31)$ \\
Total & $64(59)$ & $58(45)$ & $122(104)$
\end{tabular}

NOTE: The table provides the number of open market policy actions, as reflected in changes in the federal funds rate target, taken under symmetric and asymmetric policy directives. Numbers in parentheses give the number of such actions in which the target change exceeded 6.25 basis points. $\downarrow F F^{*}$ and $\uparrow F F^{*}$ refer to decreases and increases in the federal funds rate target, respectively.

remains whether the Committee was more likely to change its target when the directive contained asymmetric language than when it did not. Asymmetric directives were in effect on 58 percent of all business days during our sample period. If target changes were more frequent under asymmetric directives, we should find that the probability that directives were asymmetric when the Fed changed its target was significantly higher than 58 percent.

Of the 122 target changes summarized in Table 1,80 (65.6 percent) occurred under asymmetric policy directives. On eight of these occasions, however, the target was changed in the direction opposite the specified asymmetry. If these eight changes are excluded, the percentage of target changes made when the directive was asymmetric declines to 63.2 percent. A test of the hypothesis that 63.2 percent is equal to 58 percent-against the alternative that it is

\footnotetext{
${ }^{6}$ Lapp and Pearce (2000) estimate an ordered probit model of the change in the funds rate target, which includes the bias in the policy directive as an independent variable, and find that asymmetry in the directive increases the probability of a target change in the direction of the bias They do not test whether target changes are more likely, however when the directive is asymmetric.
} 
Table 2

\section{Policy Actions Taken During Intermeeting} Periods and the Bias in the Policy Directive

\begin{tabular}{lccc}
\multicolumn{3}{c}{ Policy Action Taken } \\
\hline Bias & $\downarrow F F^{*}$ & $\uparrow F F^{*}$ & Total \\
\hline Ease & $26(24)$ & $6(5)$ & $32(29)$ \\
Symmetric & $24(22)$ & $9(6)$ & $33(28)$ \\
Tight & $2(1)$ & $31(22)$ & $33(23)$ \\
Total & $52(47)$ & $46(33)$ & $98(80)$
\end{tabular}

NOTE: $\downarrow F F^{*}$ and $\uparrow F F^{*}$ refer to decreases and increases in the federal funds rate target, respectively.

higher-yields a test statistic of 1.11 , which is not statistically significant at the 5-percent level. ${ }^{7}$

If small target changes of 6.25 basis points are excluded-along with the eight changes in the direction opposite the specified bias - the probability of a target change, given that the policy directive was asymmetric, drops to 62.2 percent (61/98). Because the total number of target changes is smaller, the relevant test statistic declines to 0.85 , which is not statistically significant at the 5-percent level. ${ }^{8}$ Hence, we do not reject the null hypothesis that the inclusion of asymmetric language in the policy directive issued at the previous FOMC meeting is independent of target changes made under that directive. This conclusion is insensitive to whether small target changes (or other "technical" changes) are included or excluded.

Some observers might argue that the symmetry of the directive applied only to the intermeeting period and, hence, not to target changes made at the next meeting. Table 2 reports intermeeting target changes and the symmetry of the policy directive. Since 1983, 66.3 percent of intermeeting target changes were made when the directive was asymmetric. Omitting 6.25 basis-point target changes, and changes made in the direction opposite the specified symmetry, reduces the frequency to 62.2 percent (46 of 74 such changes).

Asymmetric directives were in effect on 58 percent of intermeeting days. A test of the null hypothesis that the true probability is 58 percent yields a test statistic of 0.72 , which is not significant at the 5-percent level. Hence, we cannot reject the hypothesis that the occurrence of intermeeting changes in the funds rate target were independent of whether the FOMC had adopted an asymmetric directive at its previous meeting. ${ }^{9}$
Since 1994, the FOMC has disclosed policy actions immediately upon making them. There have been just two intermeeting target changes since then: an increase of 25 basis points on April 18, 1994, and a 25 basis-point decrease on October 15, 1998. Consequently, since 1994 the asymmetry of the policy directive seems to have had little implication for the intermeeting period.

The relevant question for 1994-99 would seem to be whether the issuance of an asymmetric directive at one FOMC meeting increased the likelihood of a target change at the next scheduled meeting. This period (January 1994-November 1999) included 47 FOMC meetings, and the funds rate target was changed at 15 (31.9 percent) of these meetings. The language of the directive issued at the previous meeting was asymmetric at $23 \mathrm{FOMC}$ meetings, and there were eight at-meeting target changes when the directive issued at the previous meeting was asymmetric. Thus, the funds rate target was changed at eight of 23 meetings (34.8 percent) at which an asymmetric directive had been issued during the previous meeting. Although the target was changed a bit more frequently at meetings when the directive of the previous meeting was asymmetric, the difference is not statistically significant. Hence, the occurrence of target changes at FOMC meetings during this period was statistically independent of whether the directive adopted at the previous meeting was symmetric or asymmetric.

\section{SYMMETRY AND THE CHAIRMAN'S DISCRETION}

Another interpretation of asymmetric language in FOMC directives is that it gave the chairman more leeway to change the funds rate target without a Com-

\footnotetext{
${ }^{7}$ The test is based on the normal approximation to the binomial. Hence, the relevant statistic is normally distributed with a mean of zero and a variance of $p(1-p) / n$ ), where $p$ is the proportion of occurrences of the event and $n$ is the total number of opportunities. In this case, $p=0.58$ and $n=114$. If the eight target changes in the direction opposite the direction of asymmetry are not excluded, the test statistic is 1.693 , which also is not statistically significant at 5 percent.

${ }^{8}$ Using the data supplied by the staff of the FOMC Secretariat, the test statistic is 1.051 , which again is not significant at 5 percent.

${ }^{9}$ Eight target changes recorded as occurring on meeting dates were inconsistent with the directives for immediate implementation adopted at the meetings on those dates. Hence, we treat these eight as intermeeting changes (see footnote 5). Our results are not affected qualitatively, however, whether we treat these eight changes as occurring at meetings or between meetings. Similarly, if we use the data from the staff of the FOMC Secretariat, the test statistic is 1.062 , which also is not significant at 5 percent.
} 
mittee vote than when the directive was symmetric. The amount of leeway the chairman has during the intermeeting period, absent an asymmetric directive, has never been formally established. Because funds rate target changes of 25 basis points have been common (32 of 98 intermeeting target changes were of this size), however, it seems reasonable to assume that the chairman can change the funds rate target by up to 25 basis points during the intermeeting period when the policy directive is symmetric. Hence, we investigate whether target changes larger than 25 basis points in absolute value occurred more often under asymmetric directives than under symmetric directives. If larger target changes occurred only under asymmetric directives, we might infer that asymmetry was used to expand the chairman's authority to make intermeeting policy moves.

Since 1983, there were 18 target changes exceeding 25 basis points between FOMC meetings, of which 13 (72 percent) took place under asymmetric directives. Two of these changes (on March 15, 1984, and July 20, 1983) were, however, in the direction opposite the bias specified in the directive. Hence, 11 of 18 large intermeeting changes in the direction of any asymmetry (61 percent) occurred when the directive was asymmetric. Because an asymmetric policy directive was in effect on 58 percent of intermeeting days, if the size of target changes was independent of the symmetry of the policy directive, about 58 percent of large target changes should have occurred on days when the policy directive was asymmetric. Hence, the percentage of large intermeeting target changes that occurred when the directive was asymmetric was only slightly higher than chance alone would predict.

It should be noted, however, that all five large intermeeting period target changes made since Alan Greenspan became FOMC chairman in 1987 were made under asymmetric policy directives. On the other hand, since 1994, the Fed has made just two intermeeting target changes of any size, suggesting that this use of asymmetric language may have changed over time.

\section{SYMMETRY AND CONSENSUS BUILDING}

The third interpretation of asymmetric language in FOMC policy directives is that it was used to build consensus for policy directives under consideration. Consensus would be desirable if, for example, the Committee viewed its actions as more effective or more credible if dissents were rare. Symmetry might have been used to build a consensus if, for example, a majority, but not all, members of the Committee desired a change in the funds rate target. Those preferring no change might have been more willing to vote with the majority if the directive were symmetric with respect to the direction of future policy actions. Alternatively, in the event that a majority desired to maintain the existing target, but some members preferred a change, a consensus might have emerged around a directive that maintained the existing target but introduced asymmetric language concerning possible future moves. In either case, the use of symmetric or asymmetric language might, conceivably, have resulted in fewer dissents than would have occurred otherwise. ${ }^{10}$

These two examples do not cover all possible consensus-building interpretations. Suppose that all FOMC members desired to increase the funds rate target, but a majority desired a 25 basis-point increase while a minority favored a larger increase. In this case, a consensus might have emerged around a directive that called for an immediate 25 basis-point increase and asymmetry toward tightening in the future. Nevertheless, if language regarding symmetry was used to form consensus, we might expect to find that more asymmetric directives were adopted at meetings when the Committee voted to maintain the funds rate target while more symmetric directives were adopted at meetings when the Committee voted to change the funds rate target. The fact that consensus might in some circumstances have been forged by adopting asymmetric language when the target is changed would tend to bias this test against supporting the consensus-building hypothesis.

Target changes and symmetry of the policy directive voted on at meetings in our sample period are summarized in Table 3. As before, the number of changes larger than 6.25 basis points are noted in parentheses. Since 1983, there were 70 meetings at which the target was not changed and an asymmetric directive was adopted, and 15 meetings when the target was changed and a symmetric directive was adopted. Hence, 85 of 135 policy directives (63.0

\footnotetext{
10 Information on dissents by FOMC members between 1983 and 1999, classified by the four possible combinations of symmetry and target changes, are presented in Appendix A. Because a limited number of FOMC participants account for a high percentage of all dissents, dissents provide little insight into the consensus-building hypothesis. Over our sample period, five individuals accounted for 44 percent of the 112 dissents and eight individuals accounted for 60 percent of the dissents. Governor Martha Seger alone accounted for 15 percent of all dissents, dissenting at approximately 30 percent of meetings she attended, despite being a member of the FOMC during just half our sample period.
} 
Table 3

\section{Policy Actions and the Symmetry of the Policy Directive at FOMC Meetings}

\begin{tabular}{lccc}
\hline & $\Delta \boldsymbol{F} \boldsymbol{F}^{*}$ & $n o \Delta \boldsymbol{F} \boldsymbol{F}^{*}$ & Total Directives \\
\hline Asymmetric & $9(9)$ & 70 & 79 \\
Symmetric & $15(15)$ & 41 & 56 \\
Total & $24(24)$ & 111 & 135
\end{tabular}

NOTE: $\triangle F F^{*}$ and $n o \Delta F F^{*}$ refer to FOMC meetings in which the federal funds rate target was and was not changed, respectively.

percent) were consistent with consensus building. The null hypothesis that symmetry of the policy directive adopted at FOMC meetings was independent of the decision to change policy is rejected at the 5-percent significance level. The relevant test statistic is 3.01. ${ }^{11}$ Hence, the evidence supports the view that the symmetry of the policy directive was used to build consensus among the members. This conclusion is even stronger in light of the fact that the possibilities considered here do not encompass all possible cases of consensus building.

\section{SUMMARY AND CONCLUSIONS}

Between 1983 and 1999, the FOMC included language about likely future changes in policy in its operating directives to the Open Market Trading Desk. The transcript of the February 1983 FOMC meeting indicates that asymmetry was created to permit a change in the Committee's policy target between meetings if certain conditions were met. The transcript also makes clear that the Committee intended to preclude any move in the direction opposite the bias in the directive before the Committee reconvened.

Our investigation of the use of asymmetric language in FOMC policy directives has identified several patterns. First, when the FOMC issued an asymmetric directive, any policy changes at or before the next meeting were usually in the direction specified by the asymmetric language. Reductions in the federal funds rate target, for example, rarely occurred when the directive issued at the previous meeting was biased toward a tightening of policy.

We also found that policy changes occurred somewhat more frequently under asymmetric directives than under symmetric directives. For the entire sample, however, we cannot reject the hypothesis that the occurrence of either intermeeting or at-meeting policy actions was independent of whether the directive issued at the previous FOMC meeting contained asymmetric language. Similarly, for the period since 1994, when the Fed began to announce policy actions immediately upon making them, we cannot reject the hypothesis that the occurrence of policy actions was independent of whether the directive adopted at the previous meeting was asymmetric. In other words, the adoption of an asymmetric directive at one FOMC meeting appears not to have affected significantly the probability of a change in the expected federal funds rate before or at the next meeting.

We found, however, that intermeeting changes in the federal funds rate target of more than 25 basis points were more frequent under asymmetric directives than under symmetric directives. Moreover, under Alan Greenspan's tenure as chairman, all five intermeeting moves larger than 25 basis points were made under asymmetric policy directives. After 1993, however, intermeeting moves were rare, making it impossible to draw strong conclusions about asymmetric language and the chairman's discretion to make large changes in the stance of policy without an FOMC vote.

Finally, we found evidence that asymmetric language may have helped forge consensus among FOMC members for particular policy directives. Specifically, the Committee more frequently adopted asymmetric directives when it voted not to change the funds rate target. Presumably, the use of asymmetric language held the number of dissenting votes on FOMC directives below the number that would have otherwise occurred. Asymmetric language was developed to bring together disparate views among FOMC members. Since the FOMC apparently found it desirable to obtain consensus for its policy decisions, it will be interesting to see whether the FOMC will find a new method of forging consensus now that it has abandoned the use of asymmetry in its operating instructions.

\section{REFERENCES}

Greenspan, Alan. "Remarks by Chairman Alan Greenspan," at the 15th Anniversary Conference of the Center for

\footnotetext{
${ }^{11}$ Eight target changes recorded as occurring on meeting dates were inconsistent with the directives for immediate implementation adopted at the meetings on those dates. Hence, we treat these eight as intermeeting changes (see footnote 5). If they are treated instead as atmeeting changes, the relevant test statistic is 1.98 , which also is significant at the 5-percent level. Similarly, if we use the data supplied by the staff of the FOMC Secretariat, the test statistic is 2.324 , which again is significant at 5 percent.
} 
Economic Policy Research at Stanford University, September 5 , 1997. Available at <www.federalreserve.gov/boarddocs/ speeches/1997/19970905.htm> .

Lapp, John S., and Douglas K. Pearce. "Does the Bias in FOMC Policy Directives Help Predict Inter-Meeting Policy Changes?" Journal of Money, Credit and Banking (August 2000, part 1), pp. 435-41.

Meulendyke, Ann-Marie. U.S. Monetary Policy and Financial Markets, Federal Reserve Bank of New York, 1998.

Ritter, Joseph A. "The FOMC in 1992: A Monetary Conundrum," this Review (May/June 1993), pp. 31-49.

Rudebusch, Glenn D. "Federal Reserve Interest Rate Targeting, Rational Expectations, and the Term Structure," Journal of Monetary Economics (April 1995), pp. 245-74.

Sternlight, Peter D. "Monetary Policy and Open Market Operations During 1991," Federal Reserve Bank of New York Quarterly Review (Spring 1992), pp. 72-95.

Thornton, Daniel L. "The Borrowed-Reserves Operating Procedure: Theory and Evidence," this Review (Januaryl February 1988), pp. 30-54. 


\section{Appendix A}

\section{DISSENTING VOTES ON FOMC DIRECTIVES, 1983-99}

The FOMC consists of the seven members of the Board of Governors of the Federal Reserve System and the presidents of the 12 Federal Reserve Banks. All of the governors are voting members, with the Chairman of the Board of Governors, currently Alan Greenspan, serving also as chairman of the FOMC. The president of the Federal Reserve Bank of New York is the vice chairman of the FOMC and always is a voting member. The presidents of the Federal Reserve Banks of Chicago and Cleveland rotate as voting members on an annual basis. The presidents of the remaining Federal Reserve Banks rotate in groups of three, with each president voting every third year.

The members of the Board of Governors and the presidents of the Federal Reserve Banks during 198399 are listed in Table A1. The table provides the number of times each FOMC member voted against, i.e., dissented, on a monetary policy directive adopted by the FOMC during this period. Directives are classified according to whether they changed the current federal funds rate target $\left(\Delta F F^{*}\right)$, and whether they were asymmetric with respect to possible future policy action (Asym.).

\section{Table A1}

FOMC Members and Their Dissenting Votes, 1983-99

\begin{tabular}{|c|c|c|c|c|c|c|c|}
\hline Governors & $\begin{array}{l}\text { Beginning } \\
\text { of Term }\end{array}$ & $\begin{array}{l}\text { End of } \\
\text { Term }\end{array}$ & $\begin{array}{c}\Delta F^{*} \\
\text { Asym. } \\
\text { Directive }\end{array}$ & $\begin{array}{c}\Delta F^{*} \\
\text { Sym. } \\
\text { Directive }\end{array}$ & $\begin{array}{c}\text { no } \Delta F F^{*} \\
\text { Asym. } \\
\text { Directive }\end{array}$ & $\begin{array}{c}\text { no } \Delta F F^{*} \\
\text { Sym. } \\
\text { Directive }\end{array}$ & $\begin{array}{c}\text { Total } \\
\text { Dissents }\end{array}$ \\
\hline Henry C. Wallich & $03 / 08 / 74$ & $12 / 15 / 86$ & 0 & 0 & 4 & 2 & 6 \\
\hline J. Charles Partee & $01 / 05 / 76$ & $02 / 07 / 86$ & 0 & 0 & 0 & 0 & 0 \\
\hline Nancy H. Teeters & 09/18/78 & $06 / 27 / 84$ & 0 & 0 & 2 & 0 & 2 \\
\hline Emmett J. Rice & $06 / 20 / 79$ & $12 / 31 / 86$ & 0 & 0 & 2 & 0 & 2 \\
\hline Paul A. Volcker & 08/06/79 & $08 / 11 / 87$ & 0 & 0 & 0 & 0 & 0 \\
\hline Lyle E. Gramley & $05 / 28 / 80$ & 09/01/85 & 1 & 0 & 2 & 0 & 3 \\
\hline Preston Martin & $03 / 31 / 82$ & $04 / 30 / 86$ & 0 & 0 & 4 & 1 & 5 \\
\hline Martha R. Seger & $07 / 02 / 84$ & $03 / 11 / 91$ & 1 & 2 & 10 & 4 & 17 \\
\hline Wayne D. Angell & $02 / 07 / 86$ & $02 / 09 / 94$ & 1 & 1 & 4 & 2 & 8 \\
\hline Manuel H. Johnson & $02 / 07 / 86$ & 08/03/90 & 0 & 0 & 0 & 1 & 1 \\
\hline H. Robert Heller & 08/19/86 & $07 / 31 / 89$ & 0 & 0 & 0 & 0 & 0 \\
\hline Edward W. Kelley, Jr. & $05 / 26 / 87$ & & 1 & 0 & 1 & 0 & 2 \\
\hline Alan Greenspan & 08/11/87 & & 0 & 0 & 0 & 0 & 0 \\
\hline John P. LaWare & 08/15/88 & $04 / 30 / 95$ & 0 & 0 & 6 & 0 & 6 \\
\hline David W. Mullins, Jr. & $05 / 21 / 90$ & $02 / 14 / 94$ & 0 & 0 & 0 & 0 & 0 \\
\hline Lawrence B. Lindsey & $11 / 26 / 91$ & $02 / 05 / 97$ & 0 & 0 & 1 & 3 & 4 \\
\hline Susan M. Phillips & $12 / 02 / 91$ & 06/30/98 & 0 & 0 & 0 & 0 & 0 \\
\hline Alan S. Blinder & $06 / 27 / 94$ & $01 / 31 / 96$ & 0 & 0 & 0 & 0 & 0 \\
\hline Janet L. Yellin & $08 / 12 / 94$ & $02 / 17 / 97$ & 0 & 0 & 0 & 0 & 0 \\
\hline Laurence H. Meyer & $06 / 24 / 96$ & & 0 & 0 & 0 & 0 & 0 \\
\hline Alice M. Rivlin & $06 / 25 / 96$ & 07/16/99 & 0 & 0 & 0 & 0 & 0 \\
\hline Roger W. Ferguson, Jr. & $11 / 05 / 97$ & & 0 & 0 & 0 & 0 & 0 \\
\hline Edward M. Gramlich & $11 / 05 / 97$ & & 0 & 0 & 0 & 0 & 0 \\
\hline
\end{tabular}


Table A1 continued

FOMC Members and Their Dissenting Votes, 1983-99

\begin{tabular}{|c|c|c|c|c|c|c|c|c|}
\hline District & President & $\begin{array}{l}\text { Beginning } \\
\text { of Term }\end{array}$ & $\begin{array}{l}\text { End of } \\
\text { Term }\end{array}$ & $\begin{array}{c}\Delta F^{*} \\
\text { Asym. } \\
\text { Directive }\end{array}$ & $\begin{array}{c}\Delta F^{*} \\
\text { Sym. } \\
\text { Directive }\end{array}$ & $\begin{array}{c}\text { no } \Delta F F^{*} \\
\text { Asym. } \\
\text { Directive }\end{array}$ & $\begin{array}{c}\text { no } \Delta F F^{*} \\
\text { Sym. } \\
\text { Directive }\end{array}$ & $\begin{array}{c}\text { Total } \\
\text { Dissents }\end{array}$ \\
\hline \multicolumn{9}{|l|}{ Boston } \\
\hline & Frank E. Morris & 08/15/68 & $12 / 31 / 88$ & 0 & 0 & 1 & 0 & 1 \\
\hline & Richard F. Syron & 01/01/89 & $03 / 31 / 94$ & 0 & 0 & 0 & 0 & 0 \\
\hline & Cathy E. Minehan & $07 / 13 / 94$ & & 0 & 0 & 0 & 0 & 0 \\
\hline \multicolumn{9}{|l|}{ New York } \\
\hline & Anthony M. Solomon & $04 / 01 / 80$ & $01 / 01 / 85$ & 0 & 0 & 2 & 0 & 2 \\
\hline & E. Gerald Corrigan & $01 / 01 / 85$ & 07/19/93 & 0 & 0 & 0 & 0 & 0 \\
\hline & William J. McDonough & $07 / 19 / 93$ & & 0 & 0 & 0 & 0 & 0 \\
\hline \multicolumn{9}{|c|}{ Philadelphia } \\
\hline & Edward G. Boehne & $02 / 01 / 81$ & & 0 & 0 & 1 & 0 & 1 \\
\hline \multicolumn{9}{|c|}{ Cleveland } \\
\hline & Karen N. Horn & 05/01/82 & $04 / 08 / 87$ & 0 & 0 & 0 & 0 & 0 \\
\hline & W. Lee Hoskins & 09/21/87 & $11 / 15 / 91$ & 0 & 0 & 4 & 3 & 7 \\
\hline & Jerry L. Jordan & 03/10/92 & & 0 & 2 & 5 & 1 & 8 \\
\hline \multicolumn{9}{|c|}{ Richmond } \\
\hline & Robert P. Black & 08/06/73 & $12 / 31 / 92$ & 1 & 0 & 2 & 2 & 5 \\
\hline & J. Alfred Broaddus, Jr. & $01 / 01 / 93$ & & 0 & 1 & 4 & 1 & 6 \\
\hline \multicolumn{9}{|l|}{ Atlanta } \\
\hline & William F. Ford & $08 / 01 / 80$ & $10 / 01 / 83$ & 0 & 0 & 1 & 0 & 1 \\
\hline & Robert P. Forrestal & $12 / 07 / 83$ & $01 / 01 / 96$ & 0 & 0 & 0 & 0 & 0 \\
\hline & Jack Guynn & 01/01/96 & & 0 & 0 & 0 & 0 & 0 \\
\hline \multicolumn{9}{|l|}{ Chicago } \\
\hline & Silas Keehn & 07/01/81 & $08 / 31 / 94$ & 0 & 0 & 0 & 0 & 0 \\
\hline & Michael H. Moskow & 09/01/94 & & 0 & 0 & 0 & 0 & 0 \\
\hline \multicolumn{9}{|l|}{ St. Louis } \\
\hline & Theodore H. Roberts & $02 / 01 / 83$ & $12 / 31 / 84$ & 0 & 0 & 0 & 0 & 0 \\
\hline & Thomas C. Melzer & 06/01/85 & $01 / 31 / 98$ & 0 & 1 & 5 & 3 & 9 \\
\hline & William Poole & $03 / 23 / 98$ & & 0 & 0 & 1 & 0 & 1 \\
\hline \multicolumn{9}{|c|}{ Minneapolis } \\
\hline & E. Gerald Corrigan & $08 / 01 / 80$ & $12 / 31 / 84$ & 0 & 0 & 0 & 0 & 0 \\
\hline & Gary H. Stern & $03 / 21 / 85$ & & 0 & 0 & 3 & 0 & 3 \\
\hline \multicolumn{9}{|c|}{ Kansas City } \\
\hline & Roger Guffey & 03/01/76 & $10 / 01 / 91$ & 0 & 0 & 3 & 0 & 3 \\
\hline & Thomas M. Hoenig & $10 / 01 / 91$ & & 1 & 0 & 0 & 0 & 1 \\
\hline \multicolumn{9}{|l|}{ Dallas } \\
\hline & Robert H. Boykin & $01 / 01 / 81$ & $01 / 31 / 91$ & 0 & 0 & 1 & 3 & 4 \\
\hline & Robert D. McTeer, Jr. & $02 / 01 / 91$ & & 1 & 1 & 0 & 0 & 2 \\
\hline \multicolumn{9}{|c|}{ San Francisco } \\
\hline & John J. Balles & $09 / 25 / 72$ & $02 / 01 / 86$ & 0 & 0 & 0 & 0 & 0 \\
\hline & Robert T. Parry & $02 / 04 / 86$ & & 0 & 0 & 2 & 0 & 2 \\
\hline
\end{tabular}


Appendix B

\section{CHANGES IN THE EXPECTED FEDERAL FUNDS RATE, 1983-99}

When the FOMC implemented policy by establishing targets for the level of borrowed reserves, FOMC members and staff estimated the level (or range) of the federal funds rate expected to be consistent with the Committee's borrowed reserves target. Hence, changes in the expected funds rate during this period could reflect either policy changes or technical adjustments associated with achieving a given level of borrowed reserves. The FOMC did not, however, maintain a strict borrowed reserves target throughout the period studied here. At times, the Committee placed greater emphasis on the federal funds rate than on the level of borrowed reserves and, by the early 1990s, the FOMC probably had largely abandoned the targeting of borrowed reserves in favor of targeting the federal funds rate exclusively.
In this paper, we employ two distinct sets of data on changes in the expected federal funds rate. Both sets are presented below (Tables B1 and B2). The information used to construct Tables 1-3 in the text are derived from data in Rudebusch (1995) for 198493. These data have been used widely by researchers, and are based on Manager's Reports from the Open Market Trading Desk at the Federal Reserve Bank of New York. Spence Hilton of the Federal Reserve Bank of New York provided similar data to us for 1983.

A second, unofficial series on the expected federal funds rate associated with FOMC policy changes during 1983-89 was provided to us by staff of the FOMC Secretariat's office. It also is presented below.

\section{Table B1}

\section{Expected Federal Funds Rate and Dates of Changes in Expected Rate}

\begin{tabular}{|c|c|c|c|c|c|}
\hline Date of Change & $\begin{array}{l}\text { Expected } \\
\text { Funds Rate }\end{array}$ & Date of Change & $\begin{array}{l}\text { Expected } \\
\text { Funds Rate }\end{array}$ & Date of Change & $\begin{array}{l}\text { Expected } \\
\text { Funds Rate }\end{array}$ \\
\hline 07/20/1983 & 9.375 & $11 / 08 / 1984$ & 9.5 & 03/07/1986 & 7.25 \\
\hline 07/27/1983 & 9.4375 & $11 / 23 / 1984$ & 9 & 04/10/1986 & 7.125 \\
\hline 08/17/1983 & 9.5625 & $12 / 06 / 1984$ & 8.75 & 04/17/1986 & 7 \\
\hline 08/24/1983 & 9.5 & $12 / 20 / 1984$ & 8.5 & 04/24/1986 & 6.75 \\
\hline 10/05/1983 & 9.375 & $12 / 27 / 1984$ & 8.125 & 05/22/1986 & 6.8125 \\
\hline 03/01/1984 & 9.5 & $01 / 24 / 1985$ & 8.25 & 06/05/1986 & 6.875 \\
\hline 03/15/1984 & 9.875 & 02/14/1985 & 8.375 & 07/11/1986 & 6.375 \\
\hline 03/22/1984 & 10 & 02/21/1985 & 8.5 & 08/14/1986 & 6.3125 \\
\hline 03/29/1984 & 10.25 & 03/21/1985 & 8.625 & 08/21/1986 & 5.875 \\
\hline 04/05/1984 & 10.5 & 03/28/1985 & 8.5 & $12 / 04 / 1986$ & 6 \\
\hline 06/14/1984 & 10.625 & 04/18/1985 & 8.375 & 04/30/1987 & 6.5 \\
\hline 06/21/1984 & 11 & 04/25/1985 & 8.25 & 05/21/1987 & 6.75 \\
\hline 07/19/1984 & 11.25 & 05/16/1985 & 8.125 & 07/02/1987 & 6.625 \\
\hline 08/09/1984 & 11.5625 & 05/20/1985 & 7.75 & 08/27/1987 & 6.75 \\
\hline 08/30/1984 & 11.4375 & 07/11/1985 & 7.6875 & 09/03/1987 & 6.875 \\
\hline 09/20/1984 & 11.25 & 07/25/1985 & 7.75 & 09/04/1987 & 7.25 \\
\hline 09/27/1984 & 11 & 08/22/1985 & 7.8125 & 09/24/1987 & 7.3125 \\
\hline 10/04/1984 & 10.5625 & 08/29/1985 & 7.875 & 10/22/1987 & 7.125 \\
\hline 10/11/1984 & 10.5 & 09/06/1985 & 8 & 10/28/1987 & 7 \\
\hline 10/18/1984 & 10 & $12 / 18 / 1985$ & 7.75 & 11/04/1987 & 6.8125 \\
\hline
\end{tabular}




\section{Table B1 continued}

\begin{tabular}{|c|c|c|c|c|c|}
\hline Date of Change & $\begin{array}{l}\text { Expected } \\
\text { Funds Rate }\end{array}$ & Date of Change & $\begin{array}{l}\text { Expected } \\
\text { Funds Rate }\end{array}$ & Date of Change & $\begin{array}{l}\text { Expected } \\
\text { Funds Rate }\end{array}$ \\
\hline 01/28/1988 & 6.625 & $12 / 20 / 1989$ & 8.25 & 07/06/1995 & 5.75 \\
\hline 02/11/1988 & 6.5 & 07/13/1990 & 8 & $12 / 19 / 1995$ & 5.5 \\
\hline 03/30/1988 & 6.75 & 10/29/1990 & 7.75 & $01 / 31 / 1996$ & 5.25 \\
\hline 05/09/1988 & 7 & 11/14/1990 & 7.5 & 03/25/1997 & 5.5 \\
\hline 05/25/1988 & 7.25 & $12 / 07 / 1990$ & 7.25 & 09/29/1998 & 5.25 \\
\hline 06/22/1988 & 7.5 & $12 / 19 / 1990$ & 7 & 10/15/1998 & 5 \\
\hline 07/19/1988 & 7.6875 & 01/09/1991 & 6.75 & $11 / 17 / 1998$ & 4.75 \\
\hline 08/08/1988 & 7.75 & 02/01/1991 & 6.25 & 06/30/1999 & 5 \\
\hline 08/09/1988 & 8.125 & 03/08/1991 & 6 & 08/24/1999 & 5.25 \\
\hline 10/20/1988 & 8.25 & 04/30/1991 & 5.75 & $11 / 16 / 1999$ & 5.5 \\
\hline 11/17/1988 & 8.3125 & 08/06/1991 & 5.5 & & \\
\hline $11 / 22 / 1988$ & 8.375 & 09/13/1991 & 5.25 & & \\
\hline $12 / 15 / 1988$ & 8.6875 & 10/31/1991 & 5 & & \\
\hline $12 / 29 / 1988$ & 8.75 & 11/06/1991 & 4.75 & & \\
\hline 01/05/1989 & 9 & $12 / 06 / 1991$ & 4.5 & & \\
\hline 02/09/1989 & 9.0625 & $12 / 20 / 1991$ & 4 & & \\
\hline 02/14/1989 & 9.3125 & 04/09/1992 & 3.75 & & \\
\hline 02/23/1989 & 9.5625 & 07/02/1992 & 3.25 & & \\
\hline 02/24/1989 & 9.75 & 09/04/1992 & 3 & & \\
\hline 05/04/1989 & 9.8125 & 02/04/1994 & 3.25 & & \\
\hline 06/06/1989 & 9.5625 & 03/22/1994 & 3.5 & & \\
\hline 07/07/1989 & 9.3125 & 04/18/1994 & 3.75 & & \\
\hline 07/27/1989 & 9.0625 & 05/17/1994 & 4.25 & & \\
\hline 08/10/1989 & 9 & 08/16/1994 & 4.75 & & \\
\hline 10/18/1989 & 8.75 & $11 / 15 / 1994$ & 5.5 & & \\
\hline 11/06/1989 & 8.5 & 02/01/1995 & 6 & & \\
\hline
\end{tabular}


Unofficial Staff Interpretations of FOMC Policy Changes

\begin{tabular}{|c|c|c|c|}
\hline Date of Change & $\begin{array}{l}\text { Expected Funds } \\
\text { Rate or Range }\end{array}$ & Date of Change & $\begin{array}{l}\text { Expected Funds } \\
\text { Rate or Range }\end{array}$ \\
\hline 05/24/1983 & $8.5-8.75$ & Early 01/1989 & $8.875-9$ \\
\hline 06/23/1983 & 9 or slightly higher & 02/14/1989 & $9-9.125$ \\
\hline 07/13/1983 & 9 or somewhat higher & 02/24/1989 & $9.75-9.875$ \\
\hline $10 / 04 / 1983$ & $9.25-9.5$ & 06/06/1989 & $9.5-9.625$ \\
\hline 03/27/1984 & $10-10.5$ & 07/06/1989 & 9.25 \\
\hline 07/17/1984 & 11.25 & 07/27/1989 & 9 \\
\hline $10 / 02 / 1984$ & $10.5-10.625$ & 10/19/1989 & 8.75 \\
\hline 11/07/1984 & 9.5 & 11/06/1989 & 8.5 \\
\hline 11/21/1984 & 9 & 12/19/1989 & 8.25 \\
\hline $12 / 18 / 1984$ & 8.5 & & \\
\hline 02/13/1985 & $8.25-8.5$ & & \\
\hline 02/21/1985 & 8.5 & & \\
\hline 04/18/1985 & 8.25 & & \\
\hline 05/17/1985 & 7.75 & & \\
\hline 08/01/1985 & 7.75 or a shade higher & & \\
\hline 09/06/1985 & 8 & & \\
\hline $12 / 17 / 1985$ & 7.75 & & \\
\hline 03/07/1986 & 7.25 or a shade higher & & \\
\hline 04/18/1986 & 6.75 or slightly higher & & \\
\hline 06/05/1986 & 6.875 & & \\
\hline 07/10/1986 & 6.375 & & \\
\hline 08/14/1986 & $6.25-6.375$ & & \\
\hline 08/20/1986 & 5.875 & & \\
\hline 01/15/1987 & 6 & & \\
\hline 04/30/1987 & 6.5 or somewhat higher & & \\
\hline 05/19/1987 & 6.75 or somewhat lower & & \\
\hline 09/03/1987 & $6.75-7$ & & \\
\hline 09/04/1987 & 7.25 & & \\
\hline 09/22/1987 & 7.375 & & \\
\hline $10 / 23 / 1987$ & 7 & & \\
\hline 10/28/1987 & $6.75-6.875$ & & \\
\hline 01/28/1988 & $6.5-6.75$ & & \\
\hline 02/10/1988 & 6.5 & & \\
\hline 03/29/1988 & 6.75 & & \\
\hline 05/07/1988 & 7 & & \\
\hline 05/25/1988 & 7.25 & & \\
\hline 06/22/1988 & 7.5 & & \\
\hline 08/09/1988 & $8-8.25$ & & \\
\hline $11 / 22 / 1988$ & 8.375 & & \\
\hline $12 / 14 / 1988$ & $8.5-8.75$ & & \\
\hline
\end{tabular}

NOTE: The values for the federal funds rates were developed by the FOMC Secretariat on the basis of its review of FOMC meeting transcripts and other records that are available to the public, currently through 1994. The funds rates shown in the table for the period prior to mid-1989 in most cases do not reflect a decision by the FOMC to target the rates in question. They are based on staff judgments regarding the consensus of the FOMC and should not be viewed as "official" in any sense. In this paper, we assume that a target change occurred on each recorded date, including those for which a specific rate or range was not given, e.g., July 13, 1983. 